\title{
DAMPAK IMPLEMENTASI ISO/IEC 20000 PADA PERUSAHAAN PT VISIONET DATA INTERNASIONAL
}

\author{
Andreas Niko Priyohutomo ${ }^{1)}$ dan Melkior Nikolar Ngalumsine Sitokdana ${ }^{2)}$ \\ ${ }^{1,2}$ Program Studi Sistem Informasi, Fakultas Teknologi Informasi, Universitas Kristen Satya Wacana \\ ${ }^{1,2}$ Jl. Blotongan, Sidorejo Lor, Sidorejo, Kota Salatiga, Jawa Tengah 50714 \\ E-mail: 682016041@ @student.uksw.edu ${ }^{1)}$, melkior.sitokdana@uksw.edu²)
}

\begin{abstract}
ABSTRAK
PT Visionet Data Internasional merupakan perusahaan yang bergerak di bidang Information Technology (IT) yang melayani jasa total managed service. Dalam mewujudkan visi dan misi perusahaan yang efektif, perlu adanya IT Service Management (ITSM) yang memanfaatkan Teknologi Informasi yang berguna untuk memberikan informasi yang berkualitas untuk pelanggannya. Proses manajemen layanan informasi yang diberikan berupa jasa pembuatan, perbaikan dan pengembangan perangkat di bidang IT. Salah satu ITSM bisa dilakukan dengan menggunakan ISO 20000. PT Visionet Data International telah menggunakan ISO 20000 sebagai framework service pada perusahaanya. Penelitian ini menggunakan metode kualitatif deskriptif terhadap IT Compliance sebagai sumber informasi untuk penelitian ini. Pada penelitian ini menghasilkan dampak implementasi penggunaan, temuan, dan rekomendasi setelah mengimplementasikan ISO 20000 pada perusahaan PT Visionet Data International. Dalam penelitian ini, menghasilkan beberapa temuan yaitu belum semua business unit menggunakan ITSM ISO 20000, kurangnya jumlah dan pengalaman SDM dalam mengimplementasikan ITSM ISO 20000. Dari hasil penelitian ini, untuk merekomendasi penerapan ITSM ISO 20000 untuk semua business unit, open recruitment dan adanya training untuk karyawan.
\end{abstract}

Kata kunci: Service Management, ISO 20000, IEC 20000, ITSM, Dampak ITSM

\section{PENDAHULUAN}

Perkembangan Information Technology (IT) sudah menjadi hal yang tidak bisa dihindari oleh manusia. Perkembangan Teknologi Informasi saat ini telah digunakan di berbagai bidang seperti bidang pendidikan, bidang industri, bidang kesehatan bidang ekonomi dan bidang lainnya yang sangat bisa membantu meningkatkan efektifitas dan efisiensi bukan sebaliknya untuk kehidupan manusia terlebih pada organisasi. Dalam kegiatan organisasi dibutuhkan pemanfaatan teknologi dan informasi seiring perkembangan zaman dan tututan perubahan. Komponen yang terdapat pada IT juga harus dapat bersinergergi supaya teknologi dan informasi tersebut dapat berjalan dengan baik bukan sebaliknya.

Pada perusahaan menengah ke atas kebanyakan sudah menggunakan IT yang sudah maju, apalagi di era teknologi ini bisnis sudah mulai bergantung pada IT tetapi selain membutuhkan teknologi yang maju juga harus memerlukan dan memperhatikan layanan dari perusahaan.

Layanan perusahaan sudah mulai berkembang di era modern ini, dahulu layanan perusahan masih tradisional dan terkadang masih banyak kendala karena terkait manajemennya yang kurang baik, akan tetapi seiring perkembangan zaman layanan perusahaan ini sudah mulai maju dan sudah minim kendala dikarenakan manajemennya sudah membaik karena kemajuan zaman tersebut, salah satu contoh pelayanan perusahaan terkait dengan pelayanan IT, oleh karena itu perlu adanya layanan manajemen IT yang baik atau bisa disebut dengan IT Service Management (ITSM). Karena pelayanan IT harus juga diperhatikan terkait dengan kemajuan teknologi tersebut, sehingga pelayanan IT yang maju dapat berpengaruh terhadap jumlah pelanggan perusahaan.

Dalam Service IT tidak selalu berjalan dengan baik tanpa adanya manajemen yang baik oleh sebab itu perusahaan perlu adanya pengadaan service manajemen yang baik dan sesuai prosedur perusahaan, Salah satu framework untuk service manajemen IT yang baik adalah dengan menggunakan ISO 20000. Standart ini menggantikan pendahulunya yaitu BS 15000. Standart ISO 20000 terdiri dari dua bagian yaitu ISO 20000-1, menganjurkan pendekatan proses yang terintergrasi bagi pengguna agar efektif dalam menyediakan layanan sesuai dengan kebutuhan bisnis pelanggan, dan bagian kedua ISO 20000-2, adalah adanya peraturan pelaksanaan dan menjelaskan praktik-praktik yang terbaik untuk manajemen layanan lingkup ISO 20000-1.

PT Visionet Data Internasional merupakan perusahaan yang bergerak di bidang IT yang bergerak melayani jasa total managed service, PT Visionet Data Internasional melayani klien yang berfokus pada bisnis tanpa khawatir permasalahan IT mereka. Untuk layanan aplikasi bisnis yang terpadu layanan yang digunakan meliputi Enterprisse Resource Planing (ERP), Selain itu tersedia juga Costomer Reationship Management (CRM) terkait dengan peningkatan hubungan pelanggan antara pelanggan yang individual dengan pelanggan kelompok 
dengan adanya penciptaan, pengembangan dan pelanggan dengan hati-hati sehingga memaksimalkan nilai pelanggan pada jangka panjang.

PT Visionet Data Internasional telah menerima pencapaian sertifikasi IT Service Management pada ISO 20000 pada bulan Sepetember 2018. Dengan pencapaian itu PT Visionet Data Internasional merupakan salah satu perusahaan terbesar terbesar di Indonesia dengan 203 lokasi servis, 173 kota, dan 34 provinsi. Selain itu PT Visionet Data Internasional sudah diakui dan direkomendasikan oleh Gartner.Inc sebagai privider jasa service outsourcing bisnis di Indonesia karena memiliki klien 11 dari 13 bank terbesar di Indonesia.

Berdasarkan latar belakang tersebut peneliti akan melakukan analisis penelitian terhadap IT Service Management Berbasis ISO 20000 yang ada di perusahaan PT Visionet Data International bertujuan untuk mendokumentasikan standar pelayanan terhadap proses bisnis yang tarjadi pada perusahaan dan memberikan rekomendasi perbaikan berdasarkan temuan. Penelitian ini menggunakan layanan IT dan ISO 20000 sebagai bahan penelitian dan menggunakan metode deskriptif kualitatif

Dalam penelitian terdahulu ini, terdapat banyak acuan dan refrensi penulis untuk melakukan penelitian. Selain itu penelitian terdahulu ini memudahkan penulis dalam menyusun penelitian ini sehingga bisa dijadikan sebagai tolak ukur penulis dan perbandingan mengenai topik penelitian mengenai IT Service Management dari penelitian terdahulu.

Penelitian tentang merencanakan IT Service Management pada Universitas yang pernah dilakukan oleh A. Mauliawati dengan judul "Perencanaan Information Technology Service Management (ITSM) menggunakan ISO 20000 pada Universitas Terbuka" (Studi Kasus: Universitas Terbuka) tujuan dari penelitan ini adalah menghasilkan rancangan Teknologi Informasi dan Komunikasi pada Universitas Terbuka terlebih dalam SI dan TI nya serta untuk mengetahui kondisi pengelolahan layanan IT nya saat ini. Penelitian ini menghasilkan bahwa Universitas Terbuka dalam ITSM menggunakan framework ISO 2000 di lingkungan Pendidikan khususnya jarak jauh, namun masih terdapat beberapa proses yang perlu dirancang ulang. Tetapi peran dan tanggung jawab terhadap kegiatan operasional dan dukungan layanan IT sehingga akuntabilitas layanannya semakin meningkat dan layanan pada konsistensi, skalabilitas, dan reabilitas layanan terhadap customer sudah terdefinisi pada parameter pengukuran kerja (Aziz M, 2010).

Penelitian tentang dampak implementasi framework ISO 20000 yang pernah dilakukan oleh R. Yusuf dengan judul "Dampak Implementasi ISO/IEC 20000: Studi Kasus PT XYZ" tujuan dari penelitan ini adalah untuk mengetahui dampak dari penggunaan framework pada ISO 20000. Penelitian ini menghasilkan bahwa PT XYZ mempunyai kendala karena kurangnya pemahaman Top Management karena dampak penerapan implementasi
ISO 20000, lalu tidak adanya strategi yang cukup matang untuk melakukan inplementasi dan kurangnya sumber daya serta yang telah diimplementasikan ISO 20000 tidak diperhatikan masalah operasionalnya(Yusuf, 2016).

Penelitian tentang perancangan perjanjian dan standart proses pengelolahan tingkat layanan yang pernah dilakukan Erlangga Al Farozi dengan judul "Perancangan Perjanjian Tingkat Layanan dan Standart Proses Pengelolahan Tingkat Layanan Teknologi Informasi Berbasis Standart ISO 20000 dan ITIL V3 2011: Studi Kasus PT XYZ” tujuan dari penelitian ini adalah membuat perjanjian dan standart tingkat layanan PT XZY sesuai dengan implementasi ISO 20000. Penelitian ini menghasilkan bahwa PT XYZ karena tidak adanya perjanjian tingkat serta proses layanan IT yang belum formal (Farozi, 2011).

Penelitian tentang service level agreement dan proses manajemen tingkat layanan teknologi informasi berbasis standart ISO 20000 yang pernah dilakukan oleh Okky Andriawan Eka Putra dengan judul "Perancangan Service Level Agreement dan Proses Manajemen Tingkat Layanan Teknologi Informasi Berbasis Standart ISO 20000 dan ITIL V3 2011 pada Perusahaan Maskapai Penerbangan Kargo: Studi Kasus PT ABC” tujuan dari penelitian ini adalah membuat standart tingkat pengelolaan TI dan membuat dokumen perjanjian tingkat layanan (SLA) dengan kerangka ITIL V3 2011. Penelitian ini menghasilkan standar ISO 20000 terkait dengan proses manajemen tingkat layanan TI harus dijalankan oleh PT ABC, terdapat 2 layanan yaitu layanan aplikasi pegasus dan layanan email untuk dibuatkan dokumen perjanjian tingkat layanan di PT $\mathrm{ABC}$ dan terdapat 12 bagian terdiri dari ruang lingkup, deskripsi, waktu layanan, ketersediaan layanan, kehandalan layanan, dukungan pelanggan, personil yang dihungungi, keberlangsungan layanan, keamanan, cetakan, tanggung jawab dan layanan, dan proses evaluasi (Putra, 2014). Dalam refrensi tersebut peneliti berupayah untuk melakukan penelitian mengenai penerapan ISO 20000 sebagai tolak ukur pencapaian perusahaan setelah menerapkan ISO 20000.

\section{RUANG LINGKUP}

Dalam penelitian ini permasalahan mencakup:

1. Layanan TI di PT Visionet Data Internasional tidak berjalan dengan optimal tanpa adanya manajemen yang baik. Oleh sebab itu perlu adanya service manajemen sesuai standar yang baik. Salah satu framework untuk service manajemen IT yang baik adalah dengan menggunakan ISO 20000.

2. Rencana hasil yang didapatkan, yaitu mendokumentasikan standar pelayanan terhadap proses bisnis yang tarjadi pada perusahaan dan memberikan rekomendasi perbaikan berdasarkan temuan. 


\section{BAHAN DAN METODE}

Pada bagian ini menjelaskan tentang teori-teori yang berkaitan tentang topik penelitian dan metode yang digunakan, adalah sebagai berikut.

\subsection{Layanan IT dan ISO 20000}

Layanan IT adalah sarana yang diberikan oleh perusahaan atau organisasi kepada pengguna dengan cara memberikan fasilitas kepada pengguna untuk menyampaikan nilai atau manfaat tanpa adanya resiko tertentu (IT Service Management Forum, 2007). Jadi IT Service Management adalah sarana dari organisasi untuk memberikan fasilitas kepada pelanggan melalui pengembangan dan implementasi(Fidora, 2016).

Pengertian ISO yaitu "ISO" berasal dari bahasa Yunani "isos" yang memiliki arti "sama". Dari kata "sama" dalam bahasa inggris "equal" menjadi "standart". Jadi "ISO dipakai dalam perusahaan karena mudah dipahami dan juga dalam rangka menghindari penyingkatan kependekannya. Pada tahun 2005 standart ISO 20000 diterbitkan bagi organisasi untuk menetapkan, memelihara, serta meningkatkan IT Service Management, syarat yang ditemtukan dalam standart ini sudah termasuk perencanan, desain, transisi, pengiriman dan pengingkatan layanan yang berguna untuk memenuhi persyaratan dan memberikan nilai (Aziz M, 2010).

ISO 20000 adalah standar internasional yang menggambarkan praktik terbaik untuk manajemen layanan TI (ITSM). Framework ini sangat membantu organisasi untuk mengevaluasi seberapa efektif memberikan layanan terkelola, mengukur tingkat layanan dan menilai kinerja mereka. Framework ISO 20000 sangat terkait dengan ITIL (Information Technology Infrastructure Library $\left.{ }^{\circledR}\right)($ Irwin, 2019). International Organization for Standardization (ISO) 20000 memiliki persyaratan dalam standart ini yang mencakup desain, transisi, pengiriman, dan peningkatan jasa agar syarat layanan terpenuhi dan memberikan nilai kepada pelanggan dan penyedia layanan. ISO 20000 memiliki bagian yang membutuhkan pendekatan proses yang terintergrasi ketika penyedia layanan merencanakan, menetapkan mengimplementasikan, mengoprasikan, monitor, ulasan, memelihara dan mengingkatkan Service Management System (SMS). Efektifitas serta efisiensi yang lebih besar, disebabkan karena intergrasi yang terkoordinasi dan pelaksanaan SMS dapat berkelanjutan dalam memberikan kontrol dan peluang perbaikan secara terus menerus. Bagian dari ISO 20000 yang dimaksud dengan operasi proses adalah mensyaratkan personil yang akan terkoordinasi dan teroganisir dengan baik. Penyedia layanan efektif mempertimbangkan juga dampak yang ada pada SMS melalui semua tahapan hidup layanan mulai dari strategi yang melalui desain, transisi dan operasi, termasuk juga perbaikan yang bersinambungan. Proses manajemen layanan dan hubungan antara proses bisa diimplementasikan berbagaicara dengan cara yang berbeda oleh penyedia layanan. Hubungan antara penyedia layanan dan pelanggan memiliki sifat yang mempengaruhi proses manajemen pelayanan bisa ditunjukan pada Gambar 1. (Peng, 2016).

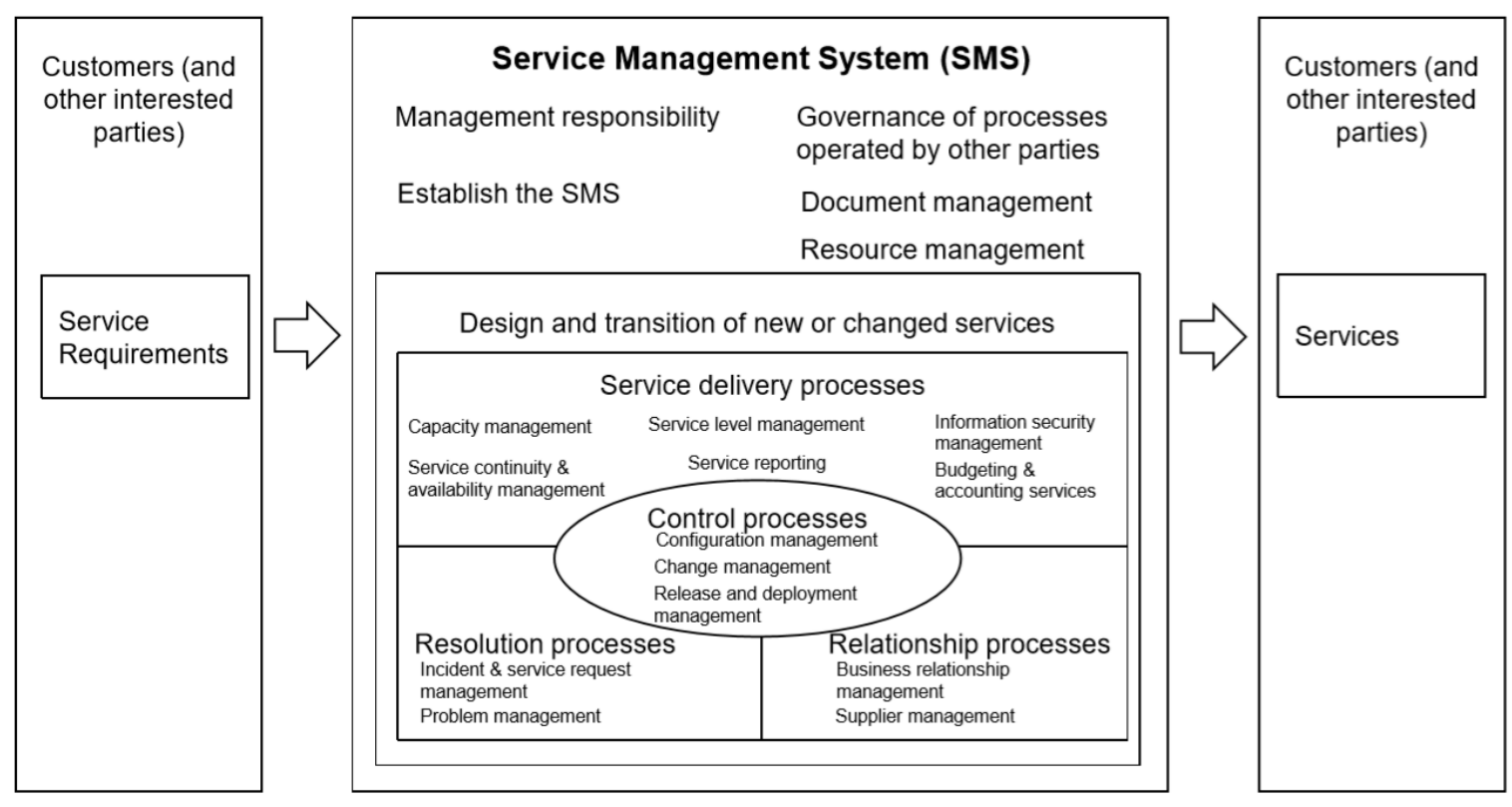

Gambar 1. Bagan proses Service Management System (SMS) 
ITIL merupakan kumpulan praktik terbaik yang memberikan suatu kerangka kerja dalam perancangan IT Service Management. Standar ini dibagi menjadi lima bagian yaitu persyaratan sistem manajemen layanan, panduan penerapan sistem manajemen layanan, pedoman definisi ruang lingkup dan penerapan ISO / IEC 2000-1 dan proses model referensi rencana implementasi contoh untuk ISO / IEC 20000-1 (Zakaria, 2017).

Organisasi menggunakan ISO 20000 untuk mengidentifikasi layanan mereka berfungsi dan dapat ditingkatkan. Sertifikasi ISO 20000 menunjukkan kepada klien bahwa organisasi berkomitmen untuk layanan berkualitas tinggi, mengurangi biaya banyak seperti standar keamanan data industri kartu pembayaran, dan memberi organisasi akses yang lebih luas ke sektor publik, karena banyak otoritas pemerintah mengharuskan penyedia layanan TI untuk patuh terhadap standar. Sertifikasi ISO / IEC 20000 memastikan pelanggan baik penglanggan internal maupun eksternal bahwa organisasi akan memberikan layanan TI pada tingkat kualitas yang memuaskan. Manfaat sertifikasi ISO / IEC 20000 meliputi arsitektur manajemen layanan TI yang efisien, handal, dan efektif, dokumentasi prosedur, perbaikan berkelanjutan, menghindari kesalahan dan insiden berulang melalui peningkatan pengetahuan manajemen, mengurangi biaya yang disebabkan oleh kurangnya efisiensi dan bukti objektif dan tidak memihak kualitas layanan TI (TÜV SÜD, 2016).

Salah satu kegiatan yang mendukung agar berjalanya ITSM ISO 20000 perlu adanya strategi manajemen yang baik pada suatu perusahaan. Strategi manajemen sendiri itu adalah suatu proses yang mengarah pada perkembangan strategi dengan cara pengambilan keputusan dan tindakan yang efektif sehingga tujuan dari perusahaan tersebut dapat tercapai. Manajemen strategi memilki beberapa dimensi dan bersifat multidimensional, yaitu adalah dimensi waktu dan orientasi masa depan, dimensi internal dan eksternal, dimensi pendayagunaan sumber-sumber, dimensi keikutsertaan manajemen puncak dan yang terakhir dimensi multi bidang. Strategi manajemen juga mempunyai karakteristik guna untuk menyikapi jika terjadi perubahan lingkungan yang dapat berpengaruh untuk manajemen suatu perusahaan, yaitu memiliki karakteristik bersifat jangka panjang, dinamik, memiliki karakteristik yang terpadu terhadap manajemen operasional, perlu unsur-unsur manajer pada tingkat puncak, berorientasi untuk masa depan, dan harus di dukung oleh sumber daya ekonomi yang ada(Taufiqurokhman, 2016).

Berdasarkan penelitian yang sudah ada bahwa IT Service Management menggunakan framework ISO 20000 sudah banyak membantu bangsa Indonesia, salah satunya pada perusahaan PT Pertamina dalam pendistribusian BBM ke seluruh Indoensia (Tahun 2013). Maka tak perlu diragukan lagi bahwa IT service Management menggunakan ISO 20000 baik digunakan untuk perusahaan-perusahaan besar di Indonesia.

\subsection{Metode dan Tahapan Penelitian}

Metode penelitian ini menggunkan metode deskriptif kualitatif karena penelitian ini berdasarkan fakta di lapangan dan juga menurut pengertian para ahli. Terdapat langkah-langkah dari metodelogi penelitian dapat dilihat pada Gambar 2.

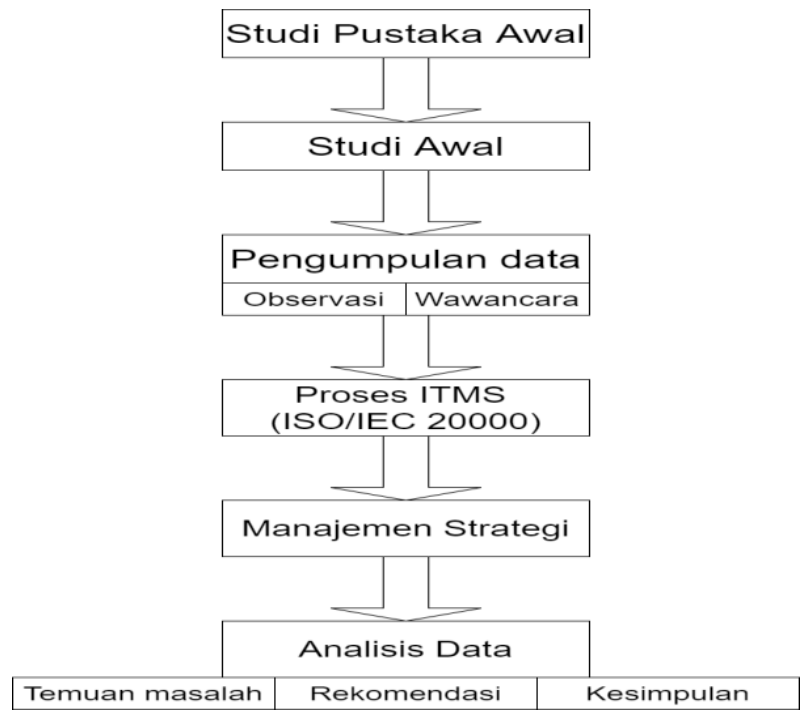

\section{Gambar 2. Tahapan penelitian}

Tahapan penelitian dan penjelasannya:

1. Studi pustaka awal

Tahap pertama untuk penelitian ini adalah melakukan pencarian studi pustaka dan mencari informasi mengenai IT Service Manajemen menggunakan framework ISO 20000. Informasi yang didapat berdasarkan karya ilmiah, jurnal dan internet.

2. Studi awal

Tahap kedua adalah studi awal yaitu peneliti mengamati dan mempelajari lingkungan yang menjadi objek peneliti.

3. Pengumpulan data

\section{1) Observasi}

Dilakukan dengan cara memantau bagaimana kinerja layanan IT untuk manajemen layanan IT dan aturan pelaksanaan untuk syarat manajemen layanan yang terdiri dari tanggung jawab manajemen mengenai sumber daya rencana tata, layanan manajemen tujuan dokumen prosedur, rencana tata dan kebijakan. Kemudian dilanjutkan dengan persyaratan dokumentasi baik itu dalam dokumentasi itu sendiri dan dari service dokumentasi dan yang terakhir mengenai kompetesi kesadaran dan pelatihan mengenai ISO 2000 itu sendiri yang berada pada PT Visionet Data International. Berdasarkan waktu dan lokasi penelitian ini dilakukan di PT Visionet Data International tepatnya di Building $C$, 5th Floor UPH Jl. MH. Thamrin No. 2, Boulevard 110, Lippo Village, Karawaci, Klp. Dua, Kec. Klp. Dua, 
Tangerang, Banten 15810 yang dilakukan dari tanggal 9 Oktober 2019 sampai dengan 2 Mei 2020.

2) Wawancara

Proses wawancara dilakukan dengan mewawancarai IT Compliance di PT Visionet Data International bersarkan proses terjadinya ISO/IEC 20000 pada perusahaan. Karena di PT Visionet Data International itu sudah menggunakan ISO 20000 sebelumnya maka dalam wawancara untuk penelitian ini hanya mengarah pada pengembangan penggunaan ISO 20000 itu sendiri agar bisa mendokumentasikan standar pelayanan terhadap proses bisnis yang tarjadi pada perusahaan dan memberikan rekomendasi perbaikan berdasarkan temuan.

4. ISO/IEC 20000 (ISO, 2011)

Proses ITSM ISO/IEC 20000 memiliki syarat pendekatan ketika penyedia layanan merencanakan, menetapkan, menerapkan, mengoperasikan, memantau, meninjau, memelihara dan meningkatkan sistem pelayanan manajemen (SMS).

5. Manajemen Strategi (David, 2014)

Teori manajemen strategi terdiri atas hal-hal berikut:

1) Menetapkan arah dan misi organisasi.

Untuk menentukan tujuan yang dituju organisasi, setiap organisasi pasti memiliki visi, misi dan tujuan untuk menentukan tujuan yang dituju dari oraganisasi itu sendiri.

2) Memahami lingkungan internal dan eksternal.

Analisis lingkungan ditujukan untuk organisasi agar dapat mudah melakukan beradaptasi terhadap perubahan. Lingkungan terbagi menjadi dua yaitu internal dan eksternal. Lingkungan internal adalah lingkungan yang berada di dalam organisasi itu sendiri, sedangkan lingkungan eksternal adalah lingkungan yang berada di luar organisasi. Terdapat dua variabel untuk lingkungan eksternal yaitu peluang (opportunity) dan acaman (threats), Lingkungan tersebut terbagi menjadi dua bagian yaitu lingkungan tugas dan lingkungan umum. Pada lingkungan internal juga terdapat dua variabel yaitu kekuatan (strength) dan kelemahan (weakness).

3) Memformulasikan strategi.

Agar tercapainya tujuan organisasi perlu adanya serangkaian tindakan yaitu dengan memformulasikan strategi. Formulasi stratgi diambil dari analisa SWOT yang meliputi pengembangan misi bisnis.

4) Mengimplementasikan strategi.

Dalam mengimplementasikan strategi, perusahaan diharapkan dapat merumuskan tujuan tahunan (annual objective of the business), memikirkan dan merumuskan kebijakan, memotivasi karyawan dan mengalosasikan sumber daya agar strategi yang telah diformulasikan dapat berjalan.

5) Mengawasi dan evaluasi strategi.

Dalam suatu proses strategi, ada tahap akhir yang harus dilakukan yaitu pengawasan dan evaluasi strategi. Pengawasan dilakukan agar strategi yang sudah diterapkan dapat berjalan dengan baik kemudian dilanjutkan dengan tahap evaluasi. Evaluasi sendiri dibagi menjadi 3 bagian yaitu melakukan ulasan terhadap faktor internal dan eksternal yang menjadi dasar strategi yang berlangsung, mengukur kinerja yang sudah dilakukan, dan melakukan tindakan perbaikan.

6. Analisis Data

1) Temuan Masalah

Pada temuan masalah ini berdasarkan tahapan penelitian melalui observasi dan wawancara sesuai dengan metode yang dilakukan oleh peneliti. Nantinya berbagai temuan positif maupun negatif dapat dijadikan suatu tindakan yang temuan positif nantinya akan dikembangkan dan temuan yang negatif dapat dijadikan rekomendasi agar dapat dibenahi. Penelitian ini menganalisis dengan cara mengelolah dengan memberikan rekomendasi dari berbagai temuan yang di dapat melalui wawancara dan kesimpulan.

2) Rekomendasi

Berdasarkan hasil analisis dari temuan masalah peneliti akan memberikan rekomendasi temuan yang negatif.

3) Kesimpulan

Merupakan tahap terakhir dalam penelitian ini, dari kesimpulan ini nantinya peneliti akan membuat kesimpulan yang dibuat berdasarkan rangkuman hasil dari analisa yang sudah dilakukan.

\section{PEMBAHASAN}

Struktur organisasi yang dimiliki oleh PT Visionet Data Internasional. Berdasarkan struktur organisasi dapat dilihat pada Gambar 3, Presiden Directur memiliki jabatan tertinggi, kemudian dibawahnya terdapat Auditor Internal dan CISO (Chief Information Security Officer), lalu dibawahnya ada BOD dan kemudian dibawahnya lagi terdapat business unit yang meliputi Business Development, Business Solution, Solution Delivery, IT Operation Managed Services, IT Applications managed services, Digital Product Innovation dan Contact Center. 


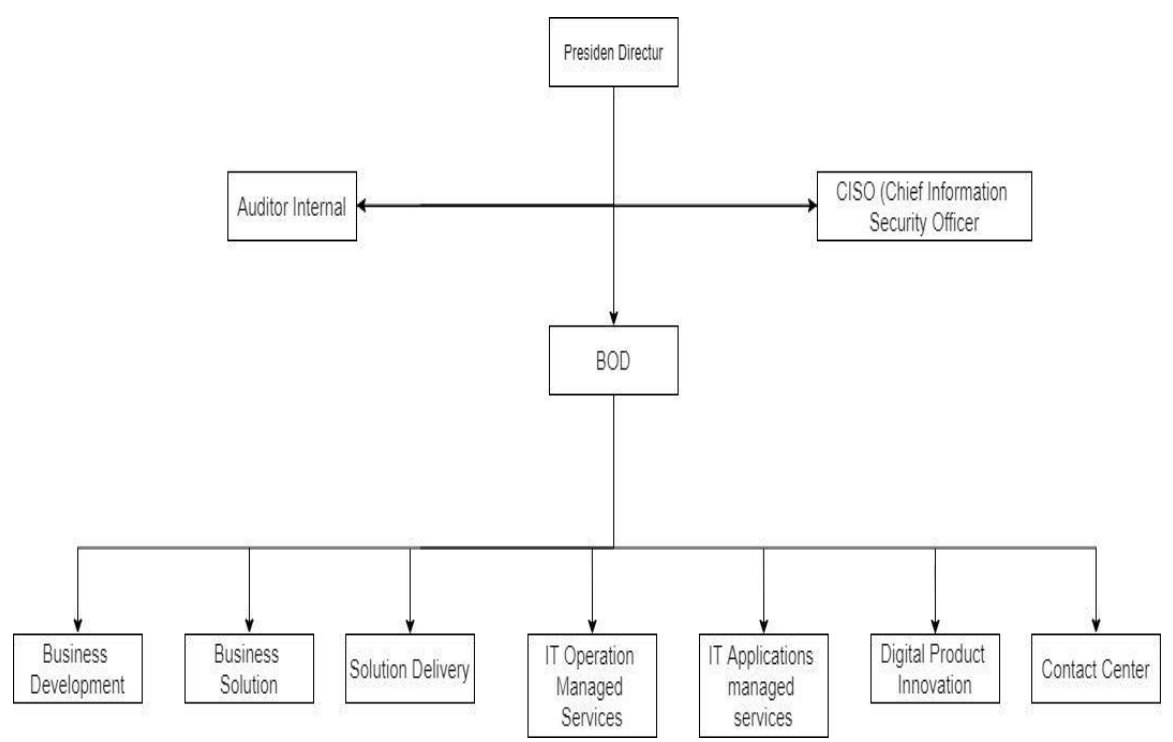

Gambar 3. Struktur organisasi

Dari struktur organisasi di atas, hanya 2 business unit yang menerapkan IT Service Management menggunakan ISO 20000 yaitu business unit IT Operation Managed Services dan IT Applications Managed Service. Penerapan yang dilakukan pada business unit dapat dilihat pada Tabel 1.

Tabel 1. Penerapan ISO 20000

\begin{tabular}{|c|c|c|c|}
\hline No & Business Unit & Department & Perubahan \\
\hline 1 & Operation Managed Services & $\begin{array}{l}\text { - Data Center Operation } \\
\text { - Server Operation } \\
\text { - Network Operation } \\
\text { - SOC (Security Operational } \\
\text { Center) } \\
\text { - Project Management } \\
\text { - Sales }\end{array}$ & \multirow{2}{*}{$\begin{array}{l}\text { Service Management Service Policy } \\
\text { - Service Management Service Plan } \\
\text { - Service Management Service Policy } \\
\text { - Design and transition of new or change Service } \\
\text { process } \\
\text { - Service local Management process } \\
\text { - IT Service continuity and availability Management } \\
\text { Management proses } \\
\text { - Capacity Management process business relationship } \\
\text { Management proses } \\
\text { - Incident and Service request } \\
\text { - Problem Management process } \\
\text { - Configuration Management process } \\
\text { - change Management process } \\
\text { - change Management Policy } \\
\text { - Release and deployment Management process } \\
\text { - Release and deploy Management Policy } \\
\text { - Incident problem management, and service reques }\end{array}$} \\
\hline 2 & $\begin{array}{l}\text { Applications Managed } \\
\text { Service }\end{array}$ & $\begin{array}{l}\text { - Fasion Retail and Financial } \\
\text { Application } \\
\text { - Food Retail Business } \\
\text { - Financial Industry } \\
\text { - Proporty Application Manage } \\
\text { Service }\end{array}$ & \\
\hline
\end{tabular}

Pada bagian strategi implementasi mengikuti teori manajemen strategi menurut (David, 2004) yang sudah disampaikan di metodelogi penelitian. Teori manajemen strategi terdiri atas hal-hal berikut:

1. Menetapkan arah dan misi organisasi.

PT Visionet Data International memiliki visi menjadi perusahaan idaman dan partner kerja yang terpercaya di dalam industri dan memiliki misi yaitu menyediakan end-to-end layanan terkelola IT yang mempercepat klien dalam meraih tujuan bisnisnya. Salah satu perubahan yang diterapkan perubahan dengan acuan pada ISO
20000. PT Visionet Data International mendapatkan sertifikasi ISO 20000 pada bulan September 2018 dan training untuk mendapatkan sertifikasi tersebut sudah di mulai perusahaan sejak tahun 2017, hal tersebut dilakukan untuk meningkatkan servicenya untuk kliennya agar perusahaan tersebut menjadi perusahaan terbaik no 1 di Indonesia di bidang IT dan banyak klien yang menggunakan jasa PT Visionet Data International sebagai tujuan bisnisnya atas kepercayaan banyak klien.

2. Memahami lingkungan internal dan eksternal.

Pada penerapan ISO 20000 ini terdapat perubahan yang cukup banyak pada struktur perusahaan dan 
prosedur-prosedur dari bisnis unit nya, PT Visionet Data International setelah menerapkan ISO 20000 terjadi perubahan pada lingkungan internal yaitu tanggung jawab karyawan lebih besar karena perusahaan kekurangan sumber daya internal, jadi karyawan tersebut melakukan double job desc, agar Service Management ISO 20000 dapat berjalan dan saat karyawan ingin menyusun dokumen-dokumen berdasarkan acuan ISO 20000 masih minta bantuan dengan konsultan ISO 20000 karena kurangnya pengalaman pada SDM, kemudian untuk di lingkungan eksternal karena perusahaan sudah tersertifikasi ISO 20000 maka ada peluang bisnis atau tender yang masuk di perushaan serta mendapatkan kepercayaan dari klien.

3. Memformulasikan strategi.

Formulasi strategi sudah dilakukan di PT Visionet Data International yang dirancang oleh top management sudah memberikan plan dan mengalokasikan untuk menerapkan iso itu, dari top management itu membentuk grup iso 20000 yang terdiri atas manajemen representatif, compliance officer, BRM (Business Relationship Manager), dan team audit internal SKAI (Satuan Kerja Audit Internal).

\section{Mengimplementasikan strategi.}

Implementasi strategi yang dilakukan perusahaan sudah diterapkan perubahan dengan acuan pada ISO 20000 pada business unit IT Operation Managed Services dan IT Applications Managed Service. PT Visionet Data International juga akan merencanakan penggunaan ISO 20000 akan digunakan di business unit lainnya seperti Business Development, Business Solution, Solution Delivery Digital Product Innovation dan Contact Center.

5. Mengawasi dan evaluasi strategi.

Melalui audit internal sebelum di lakukan audit eksternal jadi 1 tahun sekali dilakukan audit eksternal dan sudah melakukan kerjasama pada perusahaan yang sudah melaklukan sertifikasi ISO 20000 dan mereka mempunyai planning melalui pengawasan, jika ada ketidaksesuaian maka akan menerbitkan audit report dan menjelaskan ketidaksesuaian tersebut dan nantinya report tersebut akan diberikan kepada masing-masing DOC (Document Of Compliance) yang nantinya akan akan di evaluasi team manajemen mengenai ketidaksesuaian tersebut.

Dari hasil penelitian Dampak Implementasi IT Service Management berbasis ISO 20000 pada perusahaan PT Visionet Data Internasional peneliti menemukan temuan dan rekomendasi dapat dilihat pada Tabel 2.
Tabel 2. Temuan dan Rekomendasi

\begin{tabular}{|c|c|c|}
\hline No & Temuan & Rekomendasi \\
\hline 1 & $\begin{array}{l}\text { Belum semua business } \\
\text { unit yang } \\
\text { menggunakan ITSM } \\
\text { ISO 20000, jadi hanya } \\
\text { terdapat pada business } \\
\text { unit IT Operation } \\
\text { Managed Services dan } \\
\text { IT Applications } \\
\text { Managed Service. }\end{array}$ & $\begin{array}{l}\text { Adanya penerapan ITSM } \\
\text { ISO } 20000 \text { untuk lebih } \\
\text { lanjut untuk semua } \\
\text { business unit yang berada } \\
\text { pada perusahaan sehingga } \\
\text { semua business unit sudah } \\
\text { menerapkan ISO } 20000 \text {, } \\
\text { sehingga kepercayaan klien } \\
\text { pada perusahaan lebih } \\
\text { meningkat lagi. }\end{array}$ \\
\hline 2 & $\begin{array}{l}\text { Kurangnya Sumber } \\
\text { Daya Manusia (SDM) } \\
\text { yang membuat } \\
\text { karyawan tersebut } \\
\text { melakukan double job } \\
\text { desc agar ITSM ISO } \\
20000 \text { dapat berjalan }\end{array}$ & $\begin{array}{l}\text { Perlu adanya open } \\
\text { recruitment SDM sesuai } \\
\text { dengan bidangnya, agar } \\
\text { karyawan disana tidak ada } \\
\text { lagi yang melakukan tugas } \\
\text { double job, sehingga fokus } \\
\text { pada pekerjaannya, dan } \\
\text { ITSM ISO } 20000 \text { dapat } \\
\text { berjalan dengan baik. }\end{array}$ \\
\hline 3 & $\begin{array}{l}\text { Kurangnya } \\
\text { pengalaman pada } \\
\text { SDM karena saat ingin } \\
\text { menyusun dokumen- } \\
\text { dokumen berdasarkan } \\
\text { acuan ISO } 20000 \\
\text { masih minta bantuan } \\
\text { dengan konsultan ISO } \\
20000 \text {. }\end{array}$ & $\begin{array}{l}\text { Perlu adanya trainer ISO } \\
20000 \text { untuk karyawan- } \\
\text { karyawan, sehingga tidak } \\
\text { memerlukan konsultan } \\
\text { untuk menyusun dokumen- } \\
\text { dokumen berdasarkan } \\
\text { acuan ISO 20000. }\end{array}$ \\
\hline
\end{tabular}

Dari tabel 2. dapat disimpulkan bahwa hanya terdapat pada business unit IT Operation Managed Services dan IT Applications Managed Service yang menggunakan ISO 20000, kurangnya Sumber Daya Manusia (SDM) dan kurangnya pengalaman pada SDM. Maka peneliti merekomendasi untuk penerapan ITSM ISO 20000 untuk lebih lanjut untuk semua business unit yang berada pada perusahaan sehingga semua business unit sudah menerapkan ISO 20000, dan perlu adanya open recruitment serta trainer ISO 20000 untuk karyawankaryawan.

\section{KESIMPULAN}

PT Visionet Data International adalah salah satu perusahaan di bidang IT terbesar yang sudah menerapkan IT Service Manajement ISO 20000 untuk meningkatkan layanan IT mereka kepada klien. PT Visionet Data International mendapatkan sertifikasi ISO 20000 pada September 2018 dan training untuk mendapatkan sertifikasi tersebut sudah di mulai perusahaan sejak tahun 2017.

Dalam menjalankan ITSM ISO 20000 terdapat business unit IT Operation Managed Services dan IT Applications Managed Service yang sudah tersertifikasi ISO 20000, jadi belum semua business unit yang menerapkan framework ISO 20000 dan dalam kedepanya 
perusahaan akan menerapkan framework ISO 20000 untuk semua business yang ada sehingga kepercayaan klien lebih meningkat lagi. Selain itu kurang nya jumlah dan pengamalam SDM yang membuat karyawan tersebut melakukan double job desc dan meminta bantuan dengan konsultan ISO 20000 saat ingin menyusun dokumendokumen berdasarkan acuan ISO 20000. Maka dari itu hasil dari penelitian ini untuk memberikan rekomendasi untuk menerapkan ITSM ISO 20000 ke semua business unit, sehingga semua business unit sudah menerapkan ISO 20000 dan didadakannya open recruitment dan trainer SDM pada perusahaan PT Visionet Data International.

\section{SARAN}

Dampak implementasi ISO 20000 ini sangat berpengaruh terhadap perusahaan. Pelatihan ITSM yang menyeluruh sangat baik dan penting untuk pengembangan kualitas manajemen layanan IT di perusahaan.

Penelitian ini hanya menganalisis penggunaan ITSM ISO 20000 pada perusahaan PT Visionet Data International dengan kondisi yang ada saat ini. Untuk itu perlu dilakukannya penelitian lebih lanjut mengani penggunaan ITSM ISO 2000 pada perusahaan tersebut untuk mengetahui perkembangan yang terjadi pada perusahaan di waktu yang akan datang dan mungkin untuk penelitian lebih lanjut untuk menggunakan table statistic perkembangan agar lebih mudah menganalisis perkembangan perusahaan terkait dengan penggunaan ISO 20000.

\section{DAFTAR PUSTAKA}

Aziz M. 2010. Perencanaan Information Technology Service Management (ITSM) Menggunakan ISO 20000 Pada Universitas Terbuka [Universitas Islam Negeri Syarif Hidayatulah]. http://repository.uinjkt.ac.id/dspace/bitstream/1234 56789/682/1/93360-AZIZ MAULIAWATIFST.pdf

David, F. R.2014. anajemen Strategis: Konse (Edisi ketu). PT Prenhallindo.

Farozi, E. Al. 2011. Perancangan Perjanjian Tingkat Layanan dan Standart Proses Pengelolahan Tingkat Layanan Teknolgi Informasi Berbasis Standart ISO 20000 dan ITIL V3 2011 [Universitas Indonesia].

http://lib.ui.ac.id/file?file=digital/20350959-TAErlangga Al Farozi.pdf

Fidora, C. 2016. Perancangan Service Level Agreement Layanan Teknologi Informasi Berbasis ITIL V3 2011 dan ISO 20000 Studi Kasus Badan Pemeriksa Keuangan Republik Indonesia [Universitas Indonesia]. http://lib.ui.ac.id/file?file=digital/20166/20423845-TA-Cesilia Fidora.pdf

Irwin, L. 2019. “What is ISO 20000?”, . https://www.itgovernance.co.uk/blog/what-is-iso-
20000

Peng, T. 2016. ISO 20000 Service Management System. https://www.slideshare.net/thomaspeng30/iso2000012011-service-management-system-freedownload-template

Putra, O. A. E. 2014. Perancangan Service Level Agreement dan Proses Manajemen Tingkat Layanan Teknologi Berbasis ISO 2000 dan ITIL V3 2011 pada Perusahaan Maskapai Penerbangan Kargo: Studi Kasus PT ABC [Universitas Indonesia]. http://lib.ui.ac.id/file?file=digital/20367454-TAOkky Andriawan Eka Putra.pdf

Taufiqurokhman. 2016. Manajemen strategic. https://moestopo.ac.id/wpcontent/uploads/2016/09/MANAJEMENSTRATEGIK-Oleh-Dr.-Taufiqurokhman.M.Si_.pdf

TÜV SÜD. 2016. ISO 20000 IT service management. https://www.tuvsud.vn/uploads/images/1472806824456022591222/ iso-iec-20000-it-information-technology-servicemanagement-system-itsms-itil.pdf

Yusuf, R. 2016. Dampak Implementasi Iso / Iec 20000 : Studi Kasus Pt Xyz. 1-7. https://mmt.its.ac.id/publikasi/dampakimplementasi-isoiec-20000-studi-kasus-pt-xyz/

Zakaria, A. 2017. Mengenal Information Technology Infrastructure Library (ITIL V3) Secara Umum. http://smartprosolusi.com/news/mengenalinformation-technology-infrastructure-\%09libraryitil-v3-secara-umum.html. 